\title{
The Impact of Early Childhood Education on Early Achievement Gaps in Indonesia*
}

\author{
Haeil Jung \\ School of Public and Environmental Affairs \\ Indiana University Bloomington \\ 1315 E. $10^{\text {th }}$ St, SPEA 331 \\ Bloomington IN 47405 \\ Office: 812-855-1466 \\ Email: hij@indiana.edu \\ Amer Hasan \\ Education Unit \\ East Asia and Pacific Region \\ The World Bank \\ 1818 H Street, NW \\ Washington, DC 20433 \\ Email: ahasan1@worldbank.org
}

\begin{abstract}
This study assesses whether the Indonesia Early Childhood Education and Development (ECED) project had an impact on early achievement gaps as measured by an array of child development outcomes and enrollment. First, using a fixed effects model with a difference-in-difference estimator that compares children in project villages with those in non-project villages, we find that the positive impacts are concentrated among poor children. Second, extending our fixed effects model, we also find that the achievement gap in project villages decreased on many dimensions compared with the achievement gap in non-project villages.
\end{abstract}

Keywords: Early Childhood Education; Child Development; Early Achievement Gap; Indonesia; Four-Year-Old Children.

\section{Conflicts of Interest:}

Authors Haeil Jung and Amer Hasan declare that preparation of this document was partially funded by the Government of the Kingdom of the Netherlands through the Dutch Basic Education Support Program.

\footnotetext{
* This paper builds on joint work with Sally Brinkman, Marilou Hyson, Angela Kinnell, and Menno Pradhan presented in Hasan, Hyson and Chang, (eds.), 2013. The registration number of the trial on which this paper is based is ISRCTN76061874. Preparation of this document received partial funding from the Government of the Kingdom of the Netherlands through the Dutch Basic Education Support Program. We would like to thank Luis Benveniste, Marilou Hyson, Menno Pradhan, Samer Al-Samarrai, and Heather Tomlinson for detailed feedback on an earlier version of this paper. An earlier version of this paper was presented at the 2014 Population Association of America (PAA) Annual Meetings in Boston. We thank John Maluccio for his feedback as discussant. The findings, interpretations, and conclusions expressed in this paper are entirely those of the authors. They do not necessarily represent the views of the International Bank for Reconstruction and Development/World Bank and its affiliated organizations, or those of the Executive Directors of the World Bank or the governments they represent. All errors are our own.
} 


\begin{abstract}
This study assesses whether the Indonesia Early Childhood Education and Development (ECED) project had an impact on early achievement gaps as measured by an array of child development outcomes and enrollment. First, using a fixed effects model with a difference-in-difference estimator that compares children in project villages with those in non-project villages, we find that the positive impacts are concentrated among poor children. Second, extending our fixed effects model, we also find that the achievement gap in project villages decreased on many dimensions compared with the achievement gap in non-project villages.

Keywords: Early Childhood Education; Child Development; Early Achievement Gap; Indonesia; Four-Year-Old Children.
\end{abstract}

\title{
1. Introduction
}

In 2002, Indonesia made a clear commitment to education - passing a constitutional mandate to allocate at least 20 percent of the total government budget to education. This has led to a large increase in resources, more than doubling education spending in real terms. Despite such substantial financial commitments to education as a whole, a number of challenges persist. In particular, ensuring equitable access to early childhood education and development (ECED) services has historically been a challenge in Indonesia. 
To put the nature of the challenge in context, consider that in 2007 the gross enrollment rate in early childhood services for children between the ages of four and six was 23 percent. However, this number masks large differences in the probability of access depending on background. Figure 1 shows differences in the probabilities of access to early childhood services for Indonesian children of various backgrounds using 2007 data from a nationally representative household survey (SUSENAS). On average, a four-year-old child from the richest 20 percent of households in Indonesia had a 33 percent probability of accessing early childhood services while a four-year-old child from the poorest 20 percent of households in Indonesia had an 8 percent probability of accessing such services. Whether children lived in urban or rural areas made a big difference in accessing early childhood services. Above all, mothers' education level is shown as a critical predictor to explain children's enrollment in early childhood services; children whose mothers are highly educated (12 years of education) were 22 percentage points more likely to enroll in any ECED services than those whose mothers have very little education (2 years of education).

Such inequalities also exist in child developmental outcomes. As an example, Figure 2 shows the average scores of a sample of rural Indonesian children aged 48-60 months on three different measures of child development: the language and cognitive development domain of the Early Development Instrument (EDI), the draw-a-human task, and a test of executive function the Dimensional Change Card Sort game. In each panel, the performance of children between the ages of 48 and 60 months from richer households (those with a wealth index ${ }^{1}$ value above the mean) is compared to that of children from poorer households (those with a wealth index value below the mean). The data shown here suggest that child development among children from poorer households starts to plateau around the age of 54 to 56 months (four and a half years) 
whereas children from richer households continue to register improvements in their developmental outcomes as they get older.

In an effort to address such inequalities and given the government's appreciation of the importance of laying the foundation for future human capital development in early years, the government launched an Early Childhood Education and Development Project (ECED) in 3,000 poor villages in 50 districts across Indonesia in 2008. This paper investigates the data from a cohort of four-year-old children that lived in about 200 villages across rural Indonesia; only half of these villages received the project intervention. Using quasi-experimental methods, we examine the impact of the project on enrollment as well as on an array of child development outcomes to assess the degree to which this project was able to reduce gaps in child development between rich and poor children. Henceforth we refer to this gap as the early achievement gap.

The paper is structured as follows: we first review the growing literature on the impacts of early childhood services on children's development with a focus on studies that look at early achievement gaps. Next we describe the Indonesian government's approach to increasing access to early childhood services through the ECED project. We describe how the initial evaluation was designed as well as how project implementation led to deviations from the design. Then, we present quasi-experimental models that allow us to deal with these deviations from design and still causally attribute the impacts we observe to the ECED project. First, we employ a difference-in-differences (DID) approach to estimate the impact of the ECED project on any ECED enrollment and child development outcomes. Second, given our interest in assessing the degree to which this project was able to reduce early achievement gaps in child development, we construct a difference-in-difference-in-differences (DIDID) model to estimate the reductions in achievement gaps between children from rich and poor households as a result of the ECED 
project. The final section discusses our findings and assesses which aspects of project design may have contributed to the results.

\section{Literature Review}

Several researchers have found evidence of steep socioeconomic gradients in early cognitive development in countries such as Bangladesh, Brazil, Ecuador, Egypt, India, Mexico, and the Philippines (See Bouguen et al. 2013 and the references cited therein). For example, Paxson and Schady (2007) investigate trends in child development in a sample of disadvantaged Ecuadorian children using the Peabody Picture Vocabulary Test to show that while the differences in ageadjusted scores of three-year-old children are generally small, by age six children in the poorest 25 percent of households have fallen far behind children in the richest 25 percent of households. Berlinski, Galiani, and Manacorda (2008) also note that the impact of preschool attendance was largest for those children from households with less education. Most recently, Schady et al. (2014) provide new evidence of sharp differences in cognitive development by socioeconomic status in early childhood for five Latin American countries: Chile, Colombia, Ecuador, Nicaragua, and Peru.

Evidence from around the world has shown that the programs most successful at improving outcomes share several common features which include beginning at birth, involving families, and targeting the poorest children (Naudeau et. al. 2011a; Naudeau et al. 2011b). Intensive interventions which are long-lasting and holistic, meaning they include health, nutrition, and parenting services in addition to education, have been shown to have the largest and most long-lasting impacts.

In developing countries, a variety of center-based early childhood education and development services have been introduced in a multitude of contexts. Evaluations have found 
mixed evidence on the benefits of these services. For example, an evaluation from Rio Grande do Sul in Brazil (Young, 2012) compared children before and after entry into the program and showed significant cognitive, social, and motor development. Likewise, a comparison between children in the same communities who participated in the program with those that did not showed strong gains in all of these dimensions (Primeira Infância Melhor, 2011). In Mozambique, Martinez, Naudeau and Pereira (2011) found improvements in primary school enrollment rates, hours per week spent on homework as well as a number of child development outcomes as a result of preschool attendance over a two-year period. Also, Berlinski, Galiani, and Gertler (2009) showed that a large expansion of universal pre-primary education in Argentina led to an increase in average third grade test scores and improved third grader's behavior in areas such as attention, effort, class participation, and discipline. In contrast, a study on the impacts of alternative types of ECED provision in Cambodia (Bouguen et al. 2013) found little difference in development outcomes when comparing outcomes over a three-year period. More comprehensive reviews of evidence from low-income (Engle et al. 2011; Engle et al. 2007) and middle-income (Vegas and Santibáñez 2010) settings exist and underscore the variety of results reported here.

Most of the studies we reviewed have documented the impact of an early intervention on child development, but few assessed the degree to which such interventions had differing impacts on children from different socio-economic backgrounds. Burger (2010) is an exception in this regard. He analyzes the impacts of early interventions on cognitive development - one of several indicators of successful child development - and attempts to categorize programs by whether or not they had differential effects on children from different backgrounds. His study finds that socio-economically disadvantaged children made as much or slightly more progress 
than their more advantaged counterparts but such progress could not compensate for the developmental gaps between two groups. However, his focus is largely on examples from the US, Canada and Europe. ${ }^{2}$ To the best of our knowledge, few papers have systematically documented whether early childhood interventions in developing countries are able to reduce early achievement gaps.

Thus, this paper revisits the question of whether a large community-driven program which aimed to increase access to early childhood education and development services in rural areas of Indonesia improved the enrollment and child development outcomes of disadvantaged children. Then, we assess whether such services were effective in reducing early achievement gaps. In doing so, this paper contributes to the rapidly growing literature that has documented the benefits of intervening early in life to improve health and education outcomes and attempts to add to the literature on inequality in early childhood.

\section{The Indonesia Early Childhood Education and Development (ECED) Project}

\subsection{Background}

Historically, there has been a distinction drawn between formal and informal early childhood services in Indonesia. Since 2010, this distinction has been done away with at the Ministry of Education and Culture (at least on paper). Now all early childhood services are under the purview of one Directorate General at the Ministry of Education and Culture. In practice, however, the distinction between formal and informal services continues with different types of services and teachers eligible for different forms and levels of support from the government.

Each type of early childhood service is intended to cater to children of a specific age (Figure 3). In practice, these age cut-offs are hard to enforce. Some children may continue in playgroups past the intended age of four and others may enroll in primary school at the age of six 
or even five. The incentive to do so is strong since attending kindergarten is not mandatory and most kindergartens charge fees while primary school is compulsory and free.

While there are a variety of early childhood services in Indonesia, the provision of these services has historically been characterized by: 1) low levels of coverage overall, especially for children from birth to age three; 2) largely private provision of services in the face of low levels of public investment; and 3) volunteer teachers with little or no training since very few institutions provided training for early childhood teachers.

\subsection{The Scope of the Project: Selecting the Districts}

In an effort to address some of these challenges, the government of Indonesia, in partnership with the World Bank and the Dutch government, developed the ECED project. The goals of the project were to increase access to early childhood services and increase children's readiness for school in relatively poor districts with generally low ECED participation. Under this project, districts were selected on the basis of a composite score based on poverty rates, gross enrollment rates, Human Development Index (HDI) rankings, geographical remoteness, whether or not they are border districts ${ }^{3}$ and district assurance of being “committed” to early childhood services.

There were 422 districts in Indonesia at the time of the study design. The composite score was used to select 50 districts (12 percent of all districts) for inclusion in the project. Within each of these districts, 60 priority villages were identified on the basis of their poverty rate, a sufficiently large population of children between the ages of $0-6$, a sufficiently large overall population and the village's willingness to contribute financially to the project. Consequently project services were implemented in 3,000 villages (4 percent of all 69,000 villages in the country). 


\subsection{The Intervention}

Each participating district was required to set up a district-wide early childhood services office. Each village that participated in the project received the following:

1. The services of a community facilitator whose job was to raise community awareness on the importance of early childhood services and share information on the benefits available under the project. Community facilitators also provided communities with training on how to prepare proposals for the block grants available through the project.

2. Block grants for three years in the amount of $\$ 18,000$ USD per village which were to be spent on establishing two centers. Thus villages received \$3,000 USD per center per year for three years. These funds came with the requirement that no more than 20 percent could be spent on building new infrastructure. This limit meant that most of the centers established under the project involved rehabilitating existing buildings rather than constructing new ones. The remaining 80 percent could be spent on learning activities, health \& nutrition, and management \& administration of the center.

3. 200 hours of teacher training for two teachers per center. Teacher training was delivered via a cascade training model. Teachers were predominantly women from the village who often had children of their own. Some had prior work experience in health and education. Others had no such prior experience.

These three key components were designed to encourage bottom-up community services that would be sustainable and suited for each village. The original intent of the project had been to offer services to all children ages $0-6$. Communities had the discretion to choose services for children between the ages of 0-6. In practice, the most common form of service provision selected by communities was the establishment of a playgroup for four to six-year-olds, typically 
offered two hours a day, three times a week. This package (community facilitation, block grants, teacher training and playgroups) is effectively the intervention evaluated in this paper.

\subsection{The Evaluation Design}

In order to evaluate the impact of new services, given the scope of the project, the government originally decided to roll out implementation in three randomized batches (batches 1, 2 and 3) roughly nine months apart. Thus, during the design of the evaluation, the initial decision was made to randomly assign villages to planned phases of the project. Given that after this period, there would be no villages without the intervention, analysts also collected information on a group of villages that would never receive the project (about 90 non-project villages). These villages were not randomly selected. Instead they were identified by government officials as being similar to the villages that had been randomly assigned to batches 1 to 3 .

\subsection{The Evaluation in Practice}

Due to issues with timing of budget disbursements, the project design above was not adhered to. In reality, the government rolled out the program in two phases. The first roll-out comprised what was originally referred to as batch 1 and roughly half of batch 2. The second roll-out comprised the remaining half of batch 2 and batch 3. Given that project implementation deviated from its original design, for the purposes of this evaluation, we use actual date of funds disbursal to confirm when villages actually received the project. As a result, we end up with 105 villages receiving the project early (batch 1 ) and 112 villages receiving the project late (batch 3 ). There are 93 non-project villages that never received the project. At the time of this study, there have been two rounds of data collection - a baseline survey which was conducted for four year old children from March to June 2009 and a follow-up survey for the same children which was conducted from July to August 2010. 
There was also a disconnect between the timing of these surveys and the implementation of services. Villages in batch 1 implemented services about six months before the baseline survey while villages in batch 3 implemented services about nine months before the follow-up survey. Non-project villages did not receive any services. In each village, data were collected on households, caregivers and the development of two cohorts of children that were about four years old at the baseline. Since villages in batch 1 were not surveyed before the program began implementation, in this paper we examine the impact of program implementation in batch 3 (112 villages) using non-project villages (93 villages) as the comparison group.

Consequently, this paper focuses on 1) whether the package of interventions (community facilitation, block grants for playgroups and teacher training) introduced by the government had any impact on children's development and 2) whether it helped reduce early achievement gaps between children from richer and poorer households. Thus, we form our analysis sample consisting of children who were four years old in 2009 (baseline year) and likely to have attended playgroups. In this sample we have 1,184 children in the treatment group and 940 children in the comparison group.

\section{The Data: The Measures Collected and the Children}

\subsection{The Measures}

Child development was assessed using an extensive array of internationally-validated and locally-adapted ${ }^{4}$ child development measures including:

1. The short version of the Early Development Instrument (EDI)

2. The Strengths and Difficulties Questionnaire (SDQ)

3. Demonstrations of child skills (and mother reports of these skills), drawing on a study conducted by the University of San Carlos Office of Population Studies 
4. Tests of executive function using the Dimensional Change Card Sorting (DCCS) game

5. Drawing tasks (based on the Draw-a-Man test)

6. Expressive and receptive language tasks

Several of the measures above assess multiple domains of child development. A higher score is better for all measures except for the Strengths and Difficulties Questionnaire (SDQ) where lower scores are better and represent fewer difficulties. ${ }^{5}$ More specifics are presented in Table 2.2 of Hasan, Hysonn, and Chang (2013).

\subsection{The Descriptive Statistics}

Table 1 shows the descriptive statistics for enrollment and child development outcomes. We organized Table 1 into columns showing the means and standard deviations for each group of villages: treatment group villages from batch 3 and comparison group villages without the project and by the baseline and follow-up for each group to examine their similarities and differences. Our ECED enrollment variable is set to 1 if children had enrolled in any ECED service at the baseline or follow-up. Otherwise, it is set to 0 . We standardize most child development outcomes with a mean of 0 and a standard deviation of 1 among all children across the baseline and follow-up groups. This allows us to interpret the progress in different child development outcomes as a result of the ECED project with the same metric. The only exception is the test of executive function which required children to play a three-stage Dimensional Change Card Sorting game. This card sorting game is scored as 1 if the children pass at least one stage and 0 otherwise. Thus results for enrollment and carding sorting are presented in percentage point terms and results for other outcomes are presented in standard deviation units.

First, at the baseline most outcomes for children in the treatment group (batch 3 villages) are similar to those for children in the comparison group (non-project villages). As we discussed 
earlier, a group of villages was identified by government officials to make a comparison group

for batch 3 . We check whether batch 3 villages are comparable to these non-project villages in terms of enrollment and child development outcomes and find that they are very similar to each other at the baseline. None of the outcomes are statistically different between two groups. The ECED enrollment at the baseline is 34\% and 36\% for batch 3 villages and those without the project, respectively and other child development outcomes are also very similar. The close comparability of these two groups of villages is highly encouraging for us to use difference-indifferences (DID) and difference-in-difference-in-differences (DIDID) approaches to examine the impact of the ECED project on enrollment and child development outcomes.

Second, for children in the treatment and comparison groups most outcomes show improvements during the time that elapsed between the baseline and follow-up. In other words, children grew up and measures of their development improved even in the absence of the project. ECED enrollment also increases over time, even for villages that did not receive the ECED project. This reminds us that we need to control for improvements in outcomes driven only by aging. A time dummy in our DID and DIDID model controls for the effect of age.

\section{The Impact of the ECED Project on Enrollment and Child Development Outcomes}

\subsection{Statistical Model}

Before investigating whether the ECED project reduces the early child achievement gaps, we evaluate the impact of the ECED project on child development outcomes. Using batch 3 children as the treatment group and children in non-project villages as the comparison group, we estimate the impact of the ECED project using the Difference-in-Differences (DID) method. The basic idea of the DID method is to follow two groups that are similar at the baseline and then estimate the difference in outcomes at the follow-up after an intervention on one group and no 
intervention on the other. We take advantage of the fact that children in the treatment group (batch 3) had no intervention at the baseline, but had nine months of intervention at the followup, while the comparison group had no intervention either at the baseline or at the follow-up.

The regression model is as follows:

$$
\text { (1) } y_{i t}=\alpha_{i}+T_{t} \delta_{1}+D_{i} T_{t} \delta_{2}+u_{i t} \text {. }
$$

$y_{i t}$ is enrollment ( 1 if ever-enrolled and 0 if never-enrolled at time $t$ ) or child development outcomes at the baseline ( $t=1)$ and follow-up ( $t=2)$ for a child $i$. $\alpha_{i}$ controls for all the timeinvariant observed and unobserved child characteristics. $D_{i}$ is the dummy variable indicating 1 for the treatment group and 0 for the comparison group while $T_{t}$ is the dummy variable indicating 0 for the baseline and 1 for the follow-up (about 14 months apart). $\delta_{1}$ captures the age effect on child development outcomes, which includes the advancement of children's outcomes and ECED enrollment as they get older regardless of the ECED project. $D_{i} T_{t}$ is the interaction term between the intervention group dummy and the time dummy. Thus, $\delta_{2}$ is the DID parameter that captures the impact of the ECED project that had been implemented about nine months. The estimated impact of the project is not on children who are necessarily enrolled in the projectprovided services but rather it is on children who were offered a chance to enroll in the projectprovided services. This estimated impact is more relevant for policy makers since most social programs are based on the voluntary participation of eligible individuals. We use robust standard errors clustered at the individual level. The key identification assumption is that at the time of follow-up, differences in outcomes between villages that received the project in batch 3 and the comparison group should be the same as those at the baseline if there is no ECED intervention or if the intervention has no effect. 
In summary, using the DID approach we examine how the enrollment and development of children who live in the treatment group villages differs from children in the comparison group villages as they get older from age four to five. Further, we also examine subgroups of children based on their households' wealth status at the baseline because the ECED project was intended to target children from poor and disadvantaged backgrounds.

\subsection{Empirical Results}

Table 2 summarizes our findings from the DID estimates using a fixed effects model. ${ }^{6}$ DID estimates $\left(\delta_{2}\right)$ are presented for three distinct groups (a) all children, (b) children from poor households - those households that report below average wealth, and (c) children from rich households - those households that report above average wealth. DID estimates suggest that poor children made better progress in ECED enrollment and child development outcomes at the follow-up, compared to all or rich children. The impact of the ECED project on enrollment is about 6 to 7.7 percentage points higher for children from poor households at the baseline than for all four-year-old children and for rich children respectively. Also, in the domains of social competence, language \& cognitive development, communication \& general knowledge, and executive function (card sorting), we see a greater impact of the ECED project on those who are from poor households than on all or rich four-year-olds. For example, the impact of the ECED project on social competence is about 0.13 standard deviations larger for children who are from poor households than the impact for all children.

Children from poor households also made significant progress in the pro-social behavior domain of the SDQ. As mentioned earlier, negative scores in these domains indicate fewer difficulties and therefore improvements in child development. The ECED project has little impact on pro-social behavior for all four-year-old children but it greatly reduces pro-social 
behavior problems of children from poor households (statistically significant reduction of 0.210 standard deviations at $\mathrm{p}<0.05$ ). On the other hand, all or rich children had a significant reduction in conduct problems of 0.127 and 0.139 standard deviations at $\mathrm{p}<0.05$, respectively.

In order to minimize Type I error when conducting multiple hypothesis tests with similar outcome variables, we apply a Bonferroni adjustment to our results. ${ }^{7}$ In Table 2, columns marked B-A test present hypothesis tests at $\mathrm{p}<0.05$ with a Bonferroni adjustment applied. This adjustment accounts for the fact that several of the outcome variables are highly correlated to each other. The adjustment divides the p-value (0.05) by the number of outcome variables that are highly correlated to it. In this paper we designate outcomes variables with a correlation coefficient greater than 0.5 as highly correlated. In the column labeled B-A test, Yes indicates

"Reject the null hypothesis" while No indicates "Don’t reject the null hypothesis" with the adjusted significance level. For example, we find that emotional maturity is highly correlated with conduct problems and total difficulties (correlation coefficient greater than 0.5). Thus, the new significance level for the regression analysis of emotional maturity is $0.05 / 3=0.017$ with which it is harder to reject the null hypothesis; the denominator 3 comes from counting emotional maturity and the two other highly correlated variables. As shown in the table, most of estimates that are statistically significant at least at $\mathrm{p}<0.05$ are still statistically significant under B-A test. Particularly, we still have statistically significant effects of the intervention on poor children in enrollment, social competence, language \& cognitive development, communication \& general knowledge, pro-social behavior, and executive function (card sorting). This suggests that even after adjusting for multiple hypothesis testing our results hold up.

\section{The ECED Project and Early Achievement Gaps between Rich and Poor Children}

\subsection{Statistical Model}


Our findings in the previous section suggest that children from poorer households make more progress in a number of child development outcomes compared to children from rich households. Thus, in order to examine the extent to which the ECED project is able to reduce early achievement gaps, we investigate whether the project narrows the gap in child development outcomes between children from rich households and poor households based on the household wealth Z score. ${ }^{8}$ We modify our DID model to estimate the progress made by poor children relative to rich children in the treatment group (batch 3 villages) compared to such progress in the comparison group. Thus, we estimate a Difference-in-Difference-in-Differences (DIDID) model by interacting the DID variables with an indicator variable for poor children as follows: (2) $y_{i t}=\alpha_{i}+T_{t} \gamma_{1}+D_{i} T_{t} \gamma_{2}+P_{i} T_{t} \gamma_{3}+D_{i} T_{t} P_{i} \gamma_{4}+u_{i t}$.

Compared to equation (1), $P_{i}$ is a newly added dummy variable indicating 1 for poor children and 0 for rich children, which is interacted with $T_{t}$ and $D_{i} T_{t}$. In this regression model, $\gamma_{4}$ is the DIDID parameter that captures the difference in progress made by poor children relative to rich children in the treatment and comparison group villages. As in equation (1), $\alpha_{i}$ in this fixed effects model also controls for all the time-invariant observed and unobserved child characteristics.

We conducted two separate DIDID analyses. Our first analysis called Analysis (A) follows the poor household definition from the DID analysis; rich households are defined as households whose wealth is greater than or equal to the $50^{\text {th }}$ percentile and poor household are those whose wealth is lower than the $50^{\text {th }}$ percentile, respectively. In order to examine whether the impact is more concentrated on children from poorer households, our second analysis called Analysis (B) uses a new definition of rich and poor households; rich households are defined as households whose wealth is greater than the $66^{\text {th }}$ percentile and poor households are those who 
wealth is lower than the $33^{\text {rd }}$ percentile. Thus, the top and bottom one-third of households are defined as rich and poor households, respectively.

\subsection{Empirical Results}

The DIDID estimates from the fixed effects model in Table 3 present the causal reduction in the gap between rich and poor children as a result of the ECED project. Particularly, DIDID estimates in Analysis (A), the achievement gaps in ECED enrollment, social competence, language \& cognitive development, communication \& general knowledge, pro-social behavior, and draw-a-house significantly reduce by 7.7 percentage points, $0.274,0.177,0.277,0.348$, and 0.219 standard deviations, respectively. The gap in card sorting also reduces by 10.8 percentage points. In Analysis (B), the gap reductions among all children in ECED enrollment, social competence, pro-social behavior, and draw-a-house task are larger than those in Analysis (A): 14.2 percentage points, $0.361,0.509$, and 0.417 standard deviations, respectively. Such larger reductions in Analysis (B) seem to imply that the program impacts are stronger among children from poorer households.

In Table 3, as in Table 2, we apply the Bonferroni adjustment to minimize Type I error when conducting multiple hypothesis tests with similar outcome variables. Columns marked B-A test present hypothesis tests at $\mathrm{p}<0.05$ with the Bonferroni adjustment applied using the number of highly correlated outcome variables (those with a correlation coefficient greater than 0.5). Again, Yes indicates “Reject the null hypothesis” while No indicates "Don’t reject the null hypothesis” with the adjusted significance level. Even under B-A test, we still have evidence of statistically significant reduction in the gaps in terms of enrollment, social competence, communication \& general knowledge, pro-social behavior, drawing house, and executive function (card sorting) in both Analyses (A) and (B). Therefore, it appears that our estimates of 
reduction in the gaps are robust. In summary, we find that the ECED project helped children from poorer households catch up to children from richer households not only in terms of utilization of services but also in terms of child development outcomes.

\section{Discussion and Conclusion}

As this paper has shown, it is possible for well-designed early childhood services in rural areas not only to increase early achievement of disadvantaged children but also to narrow (and in some cases close) early achievement gaps. The results reported here are consistent across a number of domains. Our DID analysis examines the impact of the ECED project on children's developmental outcomes. In the domains of social competence, language and cognitive development, and executive function (card sorting), we see a greater impact of the project on children who are from poor households than on all or rich four-year-olds. The ECED project has little impact on pro-social behavior for all four-year-old children but it greatly reduces pro-social behavior problems of children from poor households. Such findings are compatible with previous studies from developing countries (for instance, Armecin et. al. 2006).

Extending the DID analysis, our DIDID analysis finds that such improvements among children from poor households lead to a statistically significant decrease in the early achievement gap between richer and poorer children. In particular, the early achievement gap in enrollment, social competence, communication \& general knowledge decreased significantly as did the early achievement gap in pro-social behavior problems. For the draw-a-house task and the card sorting game, the early achievement gap also decreased in the treatment group villages compared with the comparison group villages. Our findings from the ECED project in Indonesia are a notable addition to what Burger (2010) finds in similar research on early childhood education programs in developed countries. 
The reduction in early achievement gaps between children from poor and rich households is particularly noteworthy given that the program exposure is relatively short: 9 months. We examine below some of the factors that may explain these results. First, the project began by raising the community's awareness on the importance of preschool services. This helped ensure higher take-up rates among eligible children. Second, the vast majority of services offered by communities through the project were playgroups. These cater to children between the ages of 36 years old. Given their age, the 4-year-old children observed in our study were immediately eligible to enroll in these playgroups. This helped ensure there was little lag between the start of the project and the actual attendance of playgroups by the children we study. Third, the majority of services established under the project did not charge a fee - though this was not a project requirement. This made it possible for the poorest children - who would otherwise not be able to enroll in preschool services - to do so. Thus, this group likely also had the most to gain from project exposure. Fourth, the project provided 200 hours of teacher training for two teachers per center. This training was more intensive and structured than other existing training. Taken together, these factors might explain the magnitude of the results we obtain.

As Indonesia pursues its vision to ensure that all children have access to holistic and integrated early childhood education and development services, a number of programs and policies could be leveraged to ensure that this vision becomes a reality. The program objectives of conditional cash transfer programs and community-driven development initiatives that focus on improving access to health and education services are well-aligned with government priorities for ensuring access to early childhood services for all children. Similar programs exist in many low- and middle-income countries. Thus the opportunities described here could also be explored elsewhere. 


\section{Our findings underscore the importance of increasing access to ECED services}

\section{particularly to children from poorer backgrounds. It remains to be seen whether the kinds of}

gains found in our study persist beyond the short term analyzed here. It will also be important to

gauge whether the government is able to ensure the sustainability and utilization of these services

and expand them to reach other children in similar districts.

\footnotetext{
${ }^{1}$ Household wealth is measured using principal components analysis. A wealth measure is created using the score of the first principal component derived from a series of questions on asset ownership. The resulting score is standardized to have mean 0 and standard deviation 1. Poor households are those with a standardized wealth below 0 . Throughout this paper - rich or poor should be read as relatively richer and poorer. All households in this sample are rural Indonesian households and are broadly representative of the typical rural Indonesian household which is not rich by most definitions. However, within these rural households there are those that are relatively richer and those that are relatively poorer

${ }^{2}$ The Vietnam case in his study did not allow for sub-group comparisons.

${ }^{3}$ The government of Indonesia designates some of its poorest performing districts as 3T districts: Terpencil (isolated/remote), Terluar (border), Tertinggal (lagging).

${ }^{4}$ For details on how instruments were adapted and tested, see Pradhan et al. (2013).

${ }^{5}$ This is true of all SDQ domains. Typically one domain is reverse-scored but in this paper, we have aligned all SDQ domains in the same direction for ease of interpretation.

${ }^{6}$ All other regression estimates are available upon request. We also employ DID matching estimation methods to check whether DID estimates are robust after matching individual and family characteristics using the propensity score. Matching estimation results are compatible with the fixed effects results presented in this section. Matching estimation results are also available upon request.

${ }^{7}$ Bonferroni adjustment has been used to reduce Type I error when multiple pairwise tests are performed on a single dataset (Aickin and Gensler 1996). We apply this adjustment to reduce Type I error in our hypothesis tests.

${ }^{8}$ See footnote 1 .
} 


\section{References}

Aickin, M., and H. Gensler. 1996. “Adjusting for multiple testing when reporting research results: the Bonferroni vs Holm methods.” American Journal of Public Health 86: 726-728.

Armecin, G., J. Behrman, P. Duazo, S. Ghuman, S. Gultiano, E. King, and N. Lee. 2006. “Early Childhood Development Programs and Children’s Development: evidence from the Philippines.” World Bank Policy Research Working Paper 3922.

Berlinski, S., S. Galiani, and M. Manacorda. 2008. "Giving Children a Better Start: Preschool Attendance and School-Age Profiles.” Journal of Public Economics 92: 1416-40.

Berlinski, S., S. Galiani, and P. Gertler. 2009. “The Effect of Pre-primary Education on Primary School Performance.” Journal of Public Economics 93: 219-234.

Bouguen, A., D. Filmer, K. Macours, and S. Naudeau. 2013. “Impact Evaluation of Three Types of Early Childhood Development Interventions in Cambodia.” Washington, DC: World Bank Policy Research Working Paper Series 6540.

Burger, K. 2010. "How does early childhood care and education affect cognitive development? An international review of the effects of early interventions for children from different social backgrounds.” Early Childhood Research Quarterly 25: 140-165.

Engle, L., M. Black, R. Behrman, C. de Mello, J. Gertler, L. Kapiriri, R. Martorell, E. Young, and the International Child Development Steering Group. 2007. "Strategies to Avoid the Loss of Developmental Potential in More Than 200 Million Children in the Developing World.” Lancet 369: 229-242.

Engle, L., CH. Fernald, H. Alderman, J. Behrman, C. O'Gara, A. Yousafzai, M. Mello, M. Hidrobo, N. Ulkuer, I. Ertem, and S. Iltus, 2011. "Strategies for reducing inequalities and improving developmental outcomes for young children in low-income and middleincome countries.” Lancet 378: 1339-1353.

Hasan, A., M. Hyson, and C. Chang, eds. 2013. Providing and Evaluating Services for LowIncome Young Children. Washington DC: The World Bank.

Martinez, S., S. Naudeau, and V. Pereira. 2011. "The Promise of Preschool in Africa: A Randomised Impact Evaluation of Early Childhood Development in Rural Mozambique.” http://www.3ieimpact.org/media/filer/2013/04/11/3ie_mozambique_ie001.pdf. (Accessed on May 14, 2013.)

Naudeau, S., N. Kataoka, A. Valerio, J. Neuman, and K. Elder. 2011a. Investing in Young Children: An Early Childhood Development Guide for Policy Dialogue and Project Preparation. Washington, D.C: The World Bank.

Naudeau, S., S. Martinez, P. Premand, and D. Filmer. 2011b. “Cognitive Development among 
Young Children in Low-Income Countries.” In No Small Matter: The Impact of Poverty, Shocks, and Human Capital Investments in Early Childhood Development, edited by H. Alderman, 9-50. Washington DC: The World Bank.

Paxson, C., and N. Schady. 2007. "Cognitive Development among Young Children in Ecuador: The Roles of Wealth, Health, and Parenting.” Journal of Human Resources 42: 49-84.

Pradhan, M., A. Brinkman, A. Beatty, A. Maika, E. Satriawan, J. Ree, and A. Hasan. 2013. "Evaluating a community-based early childhood education and development program in Indonesia: Study protocol for a pragmatic cluster randomized controlled trial with supplementary matched control group.” Trials 14: 259.

Primeira Infância Melhor. 2011 vv“PIM-Programa Primeira Infância Melhor-Noticiário.” http://www.pim.saude.rs.gov.br/a_PIM/php/pagina-Noticiario.php?n=63 (Accessed on May 14, 2013.)

Schady, N., J. Behrman, C. Araujo, R. Azuero, R. Bernal, D. Bravo, F. Lopez-Boo, K. Macours, D. Marshall, C. Paxson, and R. Vakis. 2015. "Wealth Gradients in Early Childhood Cognitive Development in Five Latin American Countries." Journal of Human Resources 50: 446-463.

Vegas, E., and L. Santibáñez. 2010. The Promise of Early Child Development in Latin America and the Caribbean. Washington, DC: World Bank.

Young, M. E. 2012. "Supporting parents in Early Child Development Programs - examples of Jamaica and Brazil. Conference presentation.” Paper presented at International Early Childhood Care and Development Conference: Supporting Children's Learning and Development: Homes, Communities and Schools. Sponsored by Asia-Pacific Regional Network on Early Childhood (ARNEC), Indonesia ECCD National Coalition and World Bank. Jakarta, Indonesia. 
Figure 1: Gaps in access to early childhood services in Indonesia in 2007

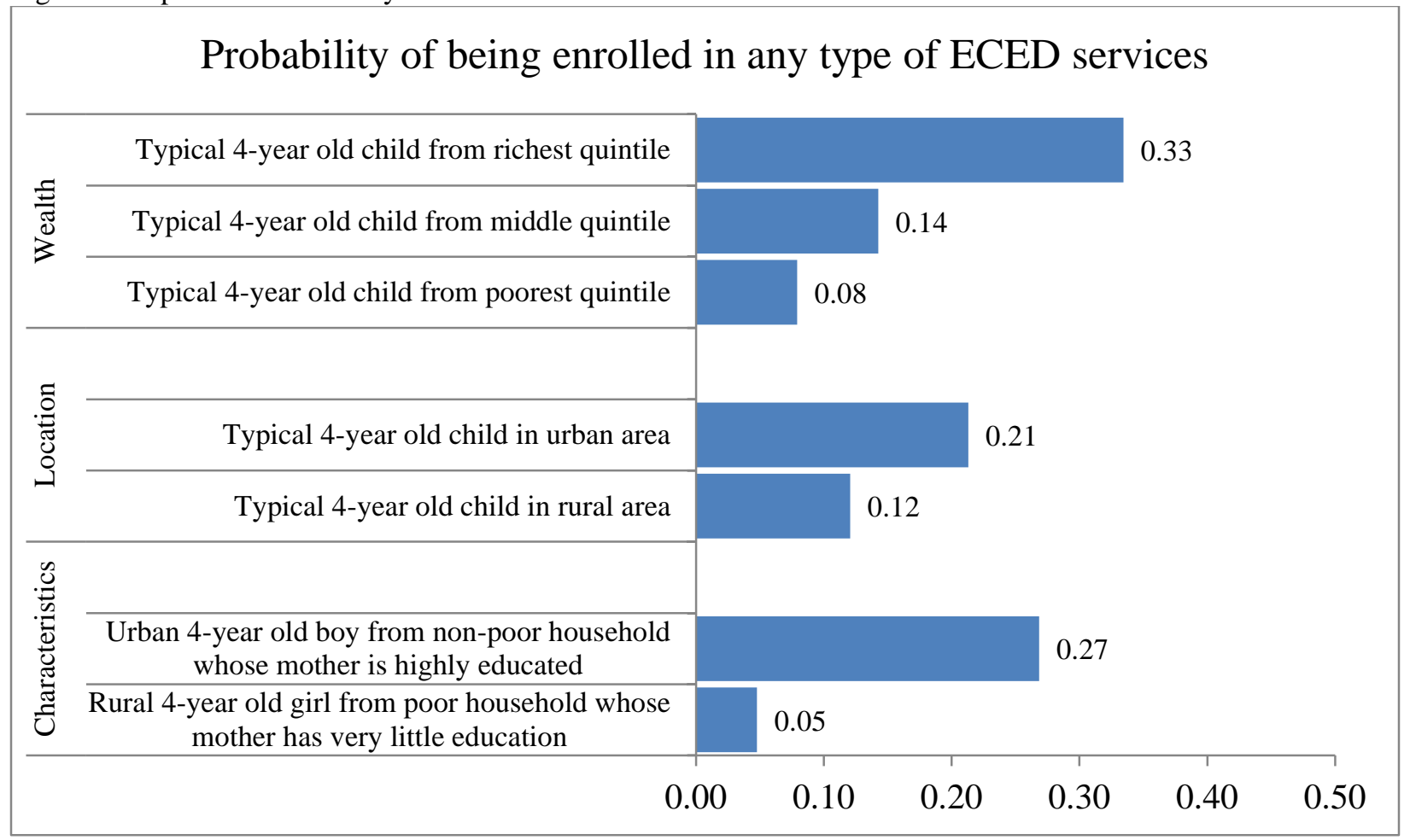

Notes: Figure shows predicted probabilities of access for different groups of children. Quintiles defined on the basis of per capita expenditure. A highly educated mother has 12 years of completed schooling. Very little education corresponds to 2 years of completed schooling. Typical child has average characteristics for the quintile or the area. Source: SUSENAS 2007 
Figure 2: Gaps between rich and poor in language and cognitive development
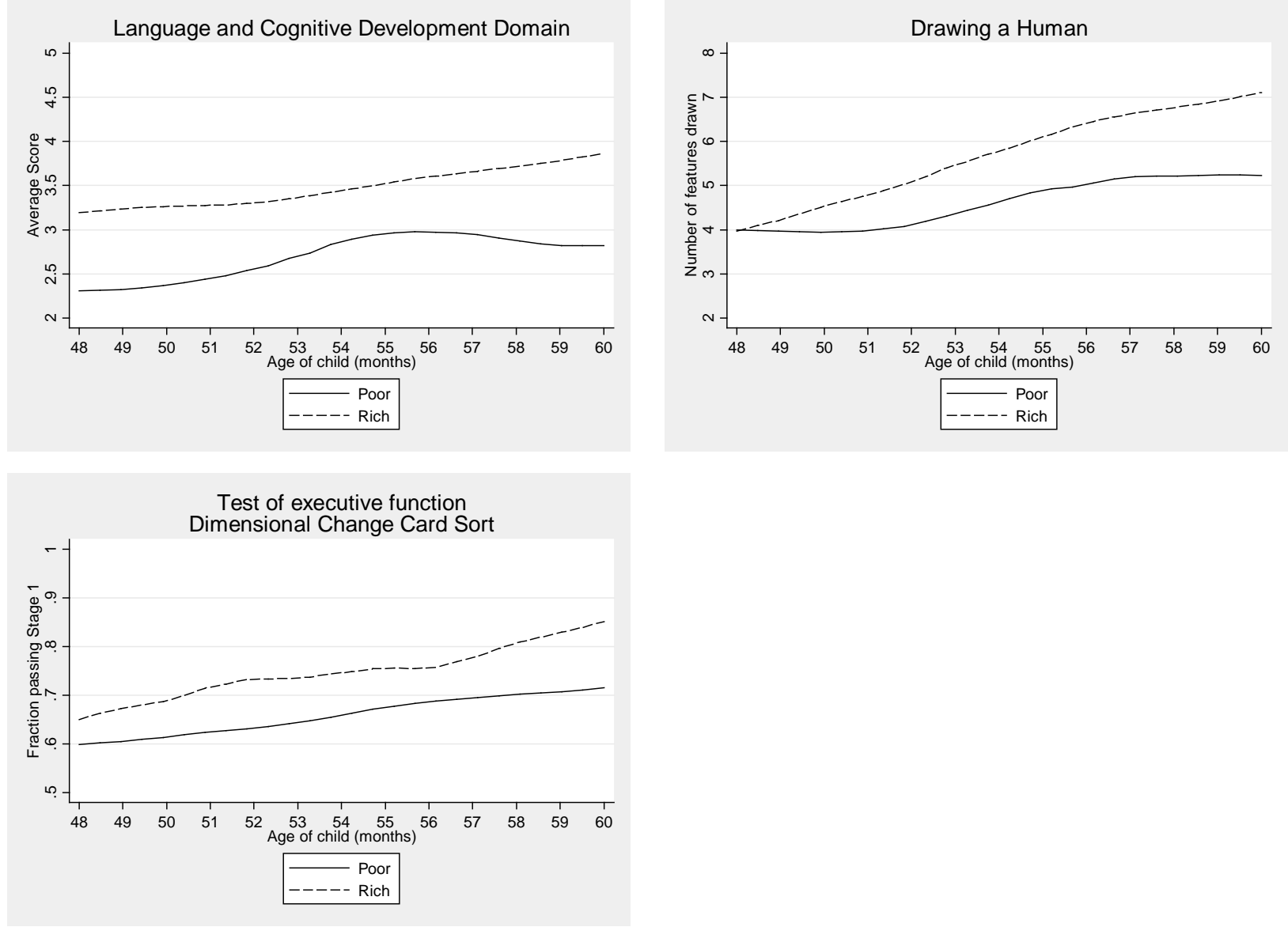

Source: ECED project baseline data from batch 3 and comparison villages. Rich have an asset index greater than or equal to 0 . Poor have an asset index less than 0 . Only children between the ages of 48 and 60 months are included. 
Figure 3: The intended age of early childhood services in Indonesia

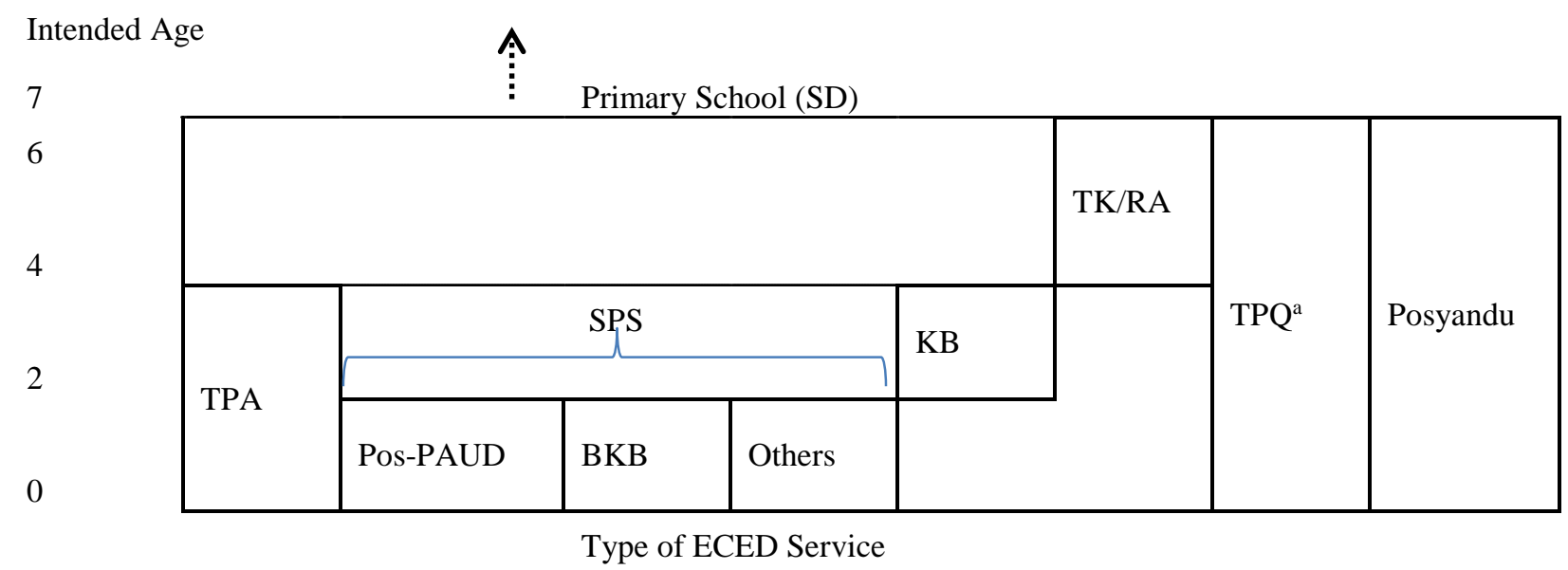

Note: a. Also included in SPS. BKB = Bina Keluarga Balita (toddler family groups); KB = Kelompok Bermain (playgroups); Pos-PAUD = ECED posts; Posyandu = (Integrated health service unit); RA = Raudhotul Atfal (Islamic kindergarten); (SPS = Satuan PAUD Sejenis (other early childhood units); TK = Taman Kanak-kanak (kindergartens); TPA = Taman Penitipan Anak (childcare centers); TPQ = Taman Pendidikan Quran (Islamic kindergartens). 
Table 1. Means and Standard Deviations of Standardized Child development outcomes.

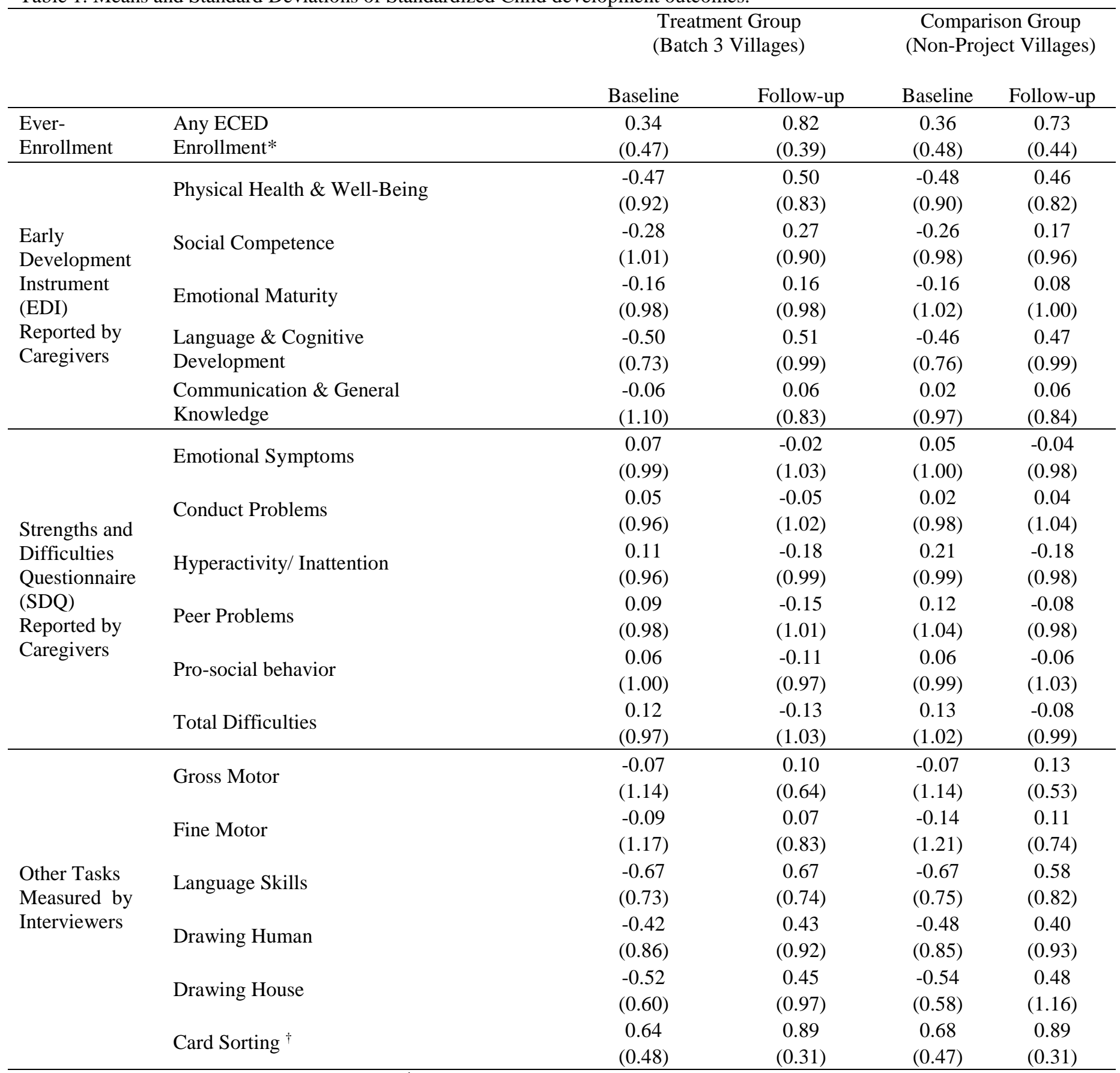

Note: Standard Deviations are in parentheses; ${ }^{\dagger}$ Dummy variables; Negative scores in SDQ domains indicate fewer difficulties and therefore improvements in child development. Sample size for batch 3 varies from 1,004 to 1,184 at the baseline 1,090 to 1,134 at the follow-up while sample size for the comparison group varies from 796 to 939 at the baseline and 840 to 893 at the follow-up. 
Table 2. DID Estimated Impact of the ECED project on Enrollment and Child Achievement Levels.

\begin{tabular}{|c|c|c|c|c|c|c|c|c|c|c|}
\hline & \multirow[b]{2}{*}{ Outcome variables } & \multicolumn{3}{|c|}{$\begin{array}{c}\text { FE } \\
\text { DID Estimate for } \\
\text { All }\left(\hat{\delta}_{2}\right)\end{array}$} & \multicolumn{3}{|c|}{$\begin{array}{c}\mathrm{FE} \\
\text { DID Estimate for } \\
\text { Poor }\left(\hat{\delta}_{2}\right)\end{array}$} & \multicolumn{3}{|c|}{$\begin{array}{c}\text { FE } \\
\text { DID Estimate for } \\
\operatorname{Rich}\left(\hat{\delta}_{2}\right)\end{array}$} \\
\hline & & Coeff & $\begin{array}{c}\text { Robust } \\
\text { SE }\end{array}$ & $\begin{array}{l}\text { B-A } \\
\text { Test }\end{array}$ & Coeff & $\begin{array}{c}\text { Robust } \\
\text { SE }\end{array}$ & $\begin{array}{l}\text { B-A } \\
\text { Test }\end{array}$ & Coeff & $\begin{array}{c}\text { Robust } \\
\text { SE }\end{array}$ & $\begin{array}{l}\text { B-A } \\
\text { Test }\end{array}$ \\
\hline Enrollment & Any ECED Enrollment ${ }^{\dagger}$ & $0.097 * * *$ & $(0.023)$ & Yes & $0.135^{* * *}$ & $(0.033)$ & Yes & $0.058^{*}$ & $(0.032)$ & No \\
\hline \multirow{6}{*}{$\begin{array}{l}\text { Early } \\
\text { Development } \\
\text { Instrument } \\
\text { (EDI) } \\
\text { Reported by } \\
\text { Caregivers }\end{array}$} & Physical Health \& Well-Being & 0.015 & $(0.050)$ & No & 0.084 & $(0.072)$ & No & -0.055 & $(0.069)$ & No \\
\hline & Social Competence & $0.107 *$ & $(0.056)$ & No & $0.239 * * *$ & $(0.084)$ & Yes & -0.026 & $(0.074)$ & No \\
\hline & Emotional Maturity & 0.083 & $(0.055)$ & No & 0.084 & $(0.080)$ & No & 0.081 & $(0.075)$ & No \\
\hline & Language \& Cognitive Development & $0.074 *$ & $(0.042)$ & No & $0.160 * * *$ & $(0.060)$ & Yes & -0.010 & $(0.058)$ & No \\
\hline & Communication \& General Knowledge & 0.074 & $(0.058)$ & No & $0.215^{* *}$ & $(0.088)$ & Yes & -0.069 & $(0.075)$ & No \\
\hline & Emotional Symptoms & -0.010 & $(0.054)$ & No & 0.009 & $(0.079)$ & No & -0.030 & $(0.075)$ & No \\
\hline \multirow{7}{*}{$\begin{array}{l}\text { Strengths and } \\
\text { Difficulties } \\
\text { Questionnaire } \\
\text { (SDQ) Reported } \\
\text { by Caregivers }\end{array}$} & Conduct Problems & $-0.127 * *$ & $(0.056)$ & No & -0.116 & $(0.079)$ & No & $-0.139 *$ & $(0.078)$ & No \\
\hline & Hyperactivity/ Inattention & 0.087 & $(0.059)$ & No & 0.042 & $(0.082)$ & No & 0.132 & $(0.085)$ & No \\
\hline & Peer Problems & -0.055 & $(0.060)$ & No & -0.049 & $(0.084)$ & No & -0.061 & $(0.085)$ & No \\
\hline & Pro-social behavior & -0.042 & $(0.060)$ & No & $-0.210 * *$ & $(0.086)$ & Yes & 0.128 & $(0.083)$ & No \\
\hline & Total Difficulties & -0.052 & $(0.054)$ & No & -0.050 & $(0.078)$ & No & -0.054 & $(0.076)$ & No \\
\hline & Gross Motor & -0.054 & $(0.059)$ & No & -0.086 & $(0.097)$ & No & -0.023 & $(0.067)$ & No \\
\hline & Fine Motor & -0.097 & $(0.063)$ & No & -0.038 & $(0.102)$ & No & $-0.155^{* *}$ & $(0.077)$ & Yes \\
\hline \multirow{4}{*}{$\begin{array}{l}\text { Other Tasks } \\
\text { Measured by } \\
\text { Interviewers }\end{array}$} & Language Skills & $0.124 * * *$ & $(0.045)$ & Yes & 0.118* & $(0.068)$ & No & $0.131^{* *}$ & $(0.058)$ & Yes \\
\hline & Drawing Human & 0.020 & $(0.052)$ & No & 0.032 & $(0.077)$ & No & 0.009 & $(0.071)$ & No \\
\hline & Drawing House & 0.019 & $(0.053)$ & No & 0.139* & $(0.073)$ & No & -0.091 & $(0.075)$ & No \\
\hline & Card Sorting $^{\dagger}$ & $0.058^{* *}$ & $(0.026)$ & Yes & $0.114^{* * *}$ & $(0.041)$ & Yes & 0.006 & $(0.033)$ & No \\
\hline
\end{tabular}

Note: ${ }^{* *} \mathrm{p}<0.01,{ }^{* *} \mathrm{p}<0.05, * \mathrm{p}<0.1$. Each row is the result of a separate regression. Sample size for all children varies from 3,775 to 4,150 while sample size for poor and rich children varies from 1,841 to 2,080 and from 1,934 to 2,070, respectively. All child development outcomes are standardized except for ECED enrollment and Card Sorting tasks marked by ${ }^{\dagger}$. Robust standard errors are clustered at the individual level. Negative scores in SDQ domains indicate fewer difficulties and therefore improvements in child development. The fixed effects models control for all the time-invariant observed and unobserved

characteristics. B-A test is a hypothesis test at $\mathrm{p}<0.05$ with Bonferroni adjustment that accounts for the number of highly correlated ( $\hat{\rho}>0.5)$ outcome variables.

This adjusted test is more conservative to reject the hull hypothesis. Yes indicates "Reject the null hypothesis" while No indicates "Don't reject the null hypothesis.” As shown in this table, some of statistically significant estimates at $\mathrm{p}<0.05$ are not statistically significant any more under B-A test. 
Table 3. DIDID Estimated Impact of the ECED on Enrollment and Child Achievement Gaps between Rich and Poor Children.

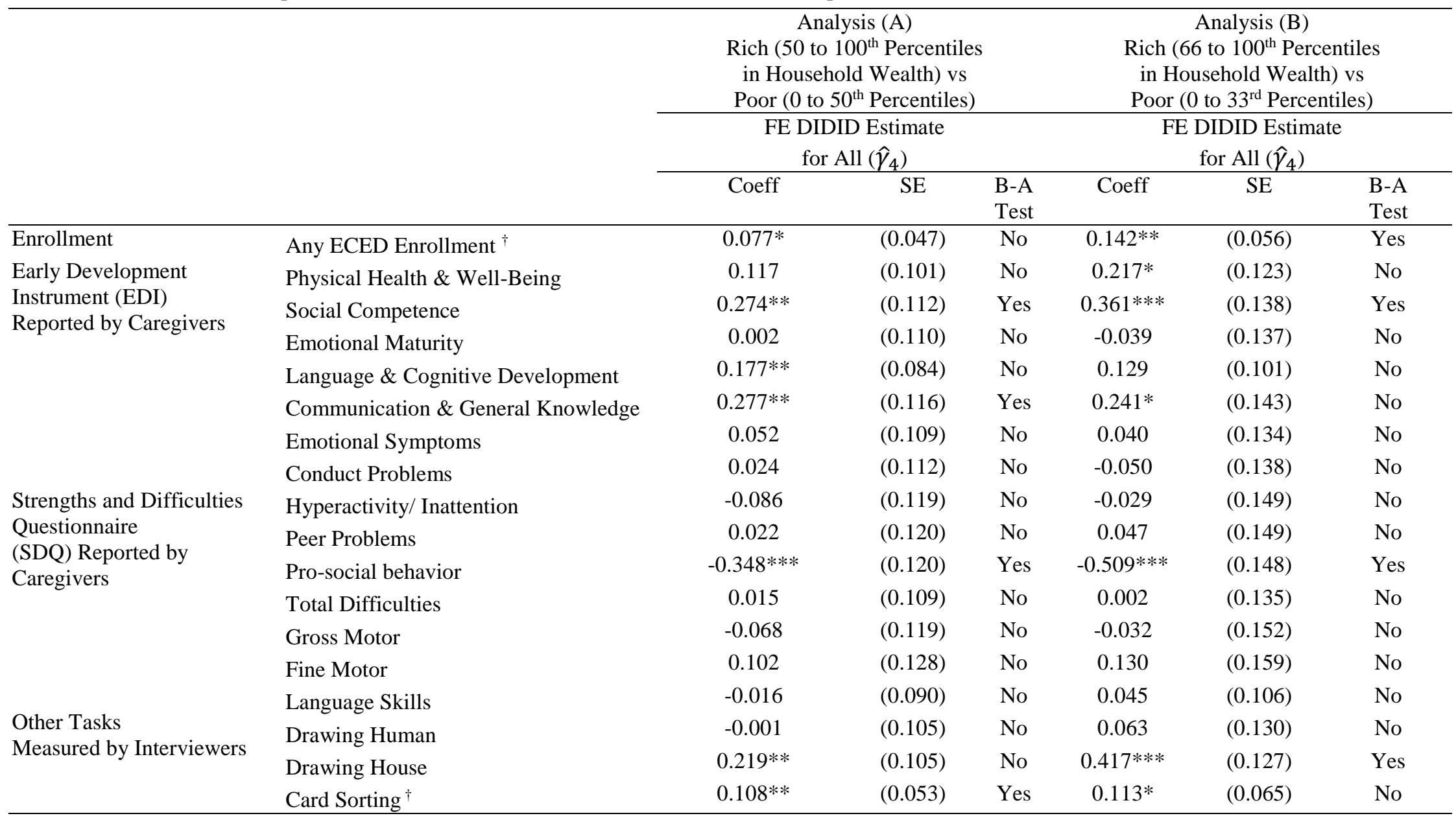

Note: *** $\mathrm{p}<0.01,{ }^{* *} \mathrm{p}<0.05, * \mathrm{p}<0.1$. Each row is the result of a separate regression. Sample size for all children in Analysis (A) varies from 3,723 to 4,904 while sample size for all children in Analysis (B) varies from 2,512 to 2,766. All child development outcomes are standardized except for ECED enrollment and Card Sorting tasks marked by ${ }^{\dagger}$. Robust standard errors are clustered at the individual level. Negative scores in SDQ domains indicate fewer difficulties and therefore improvements in child development. The fixed effects models control for all the time-invariant observed and unobserved characteristics. B-A test is a hypothesis test at $\mathrm{p}<0.05$ with Bonferroni adjustment that accounts for the number of highly correlated $(\hat{\rho}>0.5)$ outcome variables. This adjusted test is more conservative to reject the hull hypothesis. Yes indicates “Reject the null hypothesis” while No indicates “Don't reject the null hypothesis.” As shown in this table, some of statistically significant estimates at $\mathrm{p}<0.05$ are not statistically significant any more under B-A test. 